\title{
TOOL USE AND THE DEVELOPMENT OF THE FUNCTION CONCEPT: FROM REPEATED CALCULATIONS TO FUNCTIONAL THINKING
}

\author{
Received: 17 June 2011; Accepted: 30 January 2012
}

\begin{abstract}
The concept of function is a central but difficult topic in secondary school mathematics curricula, which encompasses a transition from an operational to a structural view. The question in this paper is how the use of computer tools may foster this transition. With domain-specific pedagogical knowledge on the learning of function as a point of departure and the notions of emergent modeling and instrumentation as design heuristics, a potentially rich technology-intensive learning arrangement for grade 8 students was designed and field-tested. The results suggest that the relationship between tool use and conceptual development benefits from preliminary activities, from tools offering representations that allow for progressively increasing levels of reasoning, and from intertwinement with paper-and-pencil work.
\end{abstract}

KEY WORDS: emergent modeling, function concept, instrumentation, mathematics education, technology

\section{INTRODUCTION}

The function concept is a central but difficult topic in secondary school mathematics curricula (Akkus, Hand \& Seymour, 2008; Ponce, 2007). Functions have different faces, and to make students perceive these as faces of the same mathematical concept is a pedagogical challenge. In lower secondary grades, functions mainly have an operational character and are seen as an input-output 'machine' that process input values into output values. In higher grades, functions have a more structural character with various properties (Sfard, 1991). They become mathematical objects that are represented in different ways, are ordered into different types according to their properties, and are submitted to higher-order processes such as differentiation and integration. We argue that the transition from functions as calculation operations to functions as objects is fundamental for conceptual understanding in this domain.

Can computer tools help here? Computer tools offer opportunities for thinking and learning as they can mediate the learning activities in which students engage (Sfard \& McClain, 2002). The availability of sophisticated tools for mathematics education, however, also raises questions. 
Representations and techniques in such computer environments often signify mathematical concepts that are still to be constructed in students' minds. This inherent circularity is known as the learning paradox (Bereiter, 1985; Gravemeijer et al., 2002; Heuvel-Panhuizen, 2003). The challenge, therefore, is to avoid these pitfalls and to integrate the use of computer tools in such a way that it fosters the learning of the concept of function.

The above is summarized in the research question of this study: How can a learning arrangement with computer tools foster the transition from a procedural calculation understanding to a structural correspondence and co-variation understanding of functions?

The object of study in this report is a newly designed learning arrangement in which the intertwinement of activities using both paperand-pencil and computer tools, in combination with the careful guidance by the teacher, is meant to foster grade 8 students' conceptual development of functions. We are particularly interested in activities with computer tools that help students to construct mathematical representations and actions, to explore these representations and to start reasoning with them (Falcade, Laborde, \& Mariotti, 2007).

\section{Theoretical Framework}

What theoretical perspectives may help to design and use a learning arrangement in which the use of computer tools is embedded and which fosters the transition from an operational to a structural understanding of function? First, we need domain-specific knowledge for analyzing the character of this transition. Second, from the general background of a constructivist view on learning, the notion of emergent modeling may guide the design. Third, theories on tool use and instrumentation may guide a careful integration of computer tools in the designed learning arrangement.

\section{The Concept of Function}

The teaching and learning of the concept of mathematical function is a widely researched topic. Vinner \& Dreyfuss (1989) show that students' mental images of functions may be different from its mathematical definition. Other studies confirm that students' function conceptions in many cases are limited. For example, Bloch (2003) and Skaja (2003) show that students cannot think of different functions that provide a graph through the same pair of points. Based on the model by Pirie \& Kieren 
(1989), Meel (1998) shows that many of the participants in his study held a rule-based interpretation of the function concept, which prevents them from an object-view on the concept, which is needed, among others, for the understanding of the notion of composite function. In their study on the understanding of function, Oehrtman, Carlson \& Thompson (2008) stress the relevance of students' reasoning abilities and on a conceptual orientation on the notion of function, which needs time:

We advocate for greater emphasis on enculturating students into using the language of function in order to develop facility in speaking about functions as entities that accept input and produce output, a more conceptual orientation to teaching function inverse and composition, the inclusion of tasks requiring simultaneous judgements about entire intervals of input or output values, and the development of student's ability to mentally run through a continuum of input value while imagining the changes in the output values, with explicit efforts to also promote, at developmentally appropriate time, the covariational reasoning abilities. (Oehrtman, Carlson \& Thompson, 2008, p. 39).

In line with the previous research described above, we want to design a learning arrangement for the topic of function that goes beyond the inputoutput conception, that provides room for reasoning, and that helps to overcome a too-limited concept image of function. In order to do so, Sfard's theory on the dual nature of mathematical conceptions plays a central role and is exemplified by the transition from a calculation view to an object view on function (Sfard, 1991). Sfard distinguishes operational and structural concepts, the first concerning mathematical processes and the latter mathematical objects. A function may operationally be seen as a computational process, as a recipe to transform one number into another (or to link one number to another), whereas, structurally, a function can be thought of as a set of ordered number pairs. The operational and structural conceptions are complementary. Sfard observes that, historically, the operational aspect preceded the structural aspect and argues that the same should be the case for the individual learning process, because the structural approach is more abstract than the operational. Similar dualities are described by Tall (1996) and Dubinsky (1991).

This dual nature of function appears difficult for students to comprehend. Most remain entrenched in an operational-based conception (Carlson, Jacobs, Coe, Larsen \& Hsu, 2002; Breidenbach, Dubinsky, Hawks \& Nichols, 1992). Suggestions have been made to promote operational and structural conceptualizations of functions, for example, by emphasizing the coordination of the dynamics of input-output dependency relationships (Oehrtman et al., 2008; Malle, 2000). Various viewpoints can be chosen while analyzing the dynamics, like a correspondence view and growth-oriented view (Slavit, 1997). 
Different function representations afford different views on functions. None of these, however, provides a complete description (Elia, Panaoura, Eracleous \& Gagatsis, 2007). Students will have to coordinate various representations to come to get a handle at the phenomena they are studying and to understand the relation between these phenomena and a coherent conception of functions (Duval, 2006; Even, 1998; Janvier, 1987). To the most common representations, such as verbal descriptions, tables, graphs, and formulas, Freudenthal (1983) adds the arrow chain representation, in which subsequent operations are chained. He considers the arrow chain as a didactically powerful representation for introducing the operational input-output view.

These findings focused us on the transition from operational to structural aspects of functional thinking and on the importance of using various representations. Based on these findings, our design will be guided by the following three interrelated aspects of the function concept:

- The function as an input-output assignment

The function is an input-output assignment that helps to organize and to carry out a calculation process. This initially somewhat vague and operational notion gradually gets more nuances: How does the output depend on the input; how does the input determine the output; what patterns can be seen? The representation of an inputcalculation-output chain is appropriate for this view on function.

- The function as a dynamic process of co-variation

This aspect concerns the notion that the independent variable, while running through the domain set, causes the dependent variable to run through a range set. The dependent variable co-varies with the independent. Initially, the linked change may be noticed in a somewhat phenomenological way. Next, the question emerges of how and why this process of joint dynamics takes place. Helpful representations for studying co-variation are tables and graphs, which can be scrolled through or traced.

- The function as a mathematical object

A function is a mathematical object which can be represented in different ways, such as arrow chains, tables, graphs, formulas, and phrases, each providing a different view on the same object. The more structural view on functions may be promoted by tasks focusing on a global level, for example, on families of functions, on function comparison, and later on function differentiation or integration.

In terms of Sfard's process-object duality, the input-output assignment view stresses the operational character of functions: It is an action, which 
takes the input and processes it until it becomes the output. The mathematical object view clearly relates to the structural character of the function: It is a 'thing', which can be member of a family, or be submitted to higher-order processes such as differentiation.

Different function representations stress different aspects and uses of the function concept. For example, one single arrow chain is suitable to an operational, process view, while a family of graphs is more holistic in nature and more suitable to a structural perspective.

\section{Emergent Modeling}

Emergent modeling is a design heuristic which originated in the frame of the theory of realistic mathematics education (RME) (Gravemeijer 1999, 2007). RME builds on Freudenthal's (1991) image of mathematics as 'a human activity': While engaging in mathematics as an activity, students should be supported in reinventing mathematics. The emergent modeling design heuristic is a means for organizing such a reinvention process. The approach takes its starting point in the activity of modeling contextual problems. In this setup, models initially come to the fore as context-specific models that refer to realistic or paradigmatic situations. Then, while the students gather more experience with similar problems, attention may be shifted toward the mathematical relations involved. This helps them to further develop those mathematical relations, which enables them to use the model in a different manner. The model starts to derive its meaning from these mathematical relations and becomes a base for more formal mathematical reasoning. Or in short: A model of informal mathematical activity develops into a model for more formal mathematical reasoning (e.g. Gravemeijer, 1999; Cobb, 2002; Rasmussen \& Blumenfeld, 2007; Doorman \& Gravemeijer, 2009). The learning paradox, as described in the "Introduction," can be circumvented by designing a chain of activities and a process of emergent modeling that fosters a reflexive process in which representations and meaning co-evolve (Cobb, 2002; Meira, 1995). This approach is consistent with conceptual change literature, which argues that students must first explore a domain and recognize limitations or a need for more sophisticated tools, before they are ready to learn complex concepts (Lehrer \& Schauble, 2002).

In this study, the notion of emergent modeling is used as an important design heuristic. It stresses the importance of starting with contextual problems that offer opportunities to develop situation-specific reasoning and tentative representations for organizing repeated calculations and that have the potential to evoke the need for more sophisticated - mathematical - tools and concepts (Gravemeijer, 2007). For instance, the table representation is 
initially understood as a tool for administrating values of two quantities (like time and temperature). In a learning arrangement on functions, the table can come to the fore as a tool for organizing corresponding input-output values in contextual problems. Next, on the computer, this table can be used as a tool for scrolling and zooming in or out these values for various purposes (e. g. analyzing growth behavior or finding break-even points). This imagerytable and actions - initially signifies repeated calculations and emerges into a model for a structural understanding of dependency relationships. Taking this process seriously asks for a design in which a table tool is not introduced too quickly, but builds upon previous activities.

\section{Tools and Instrumentation}

Emergent modeling as a design heuristic does not particularly focus on the use of computer tools and the relationship between computer techniques, paper-and-pencil techniques, and conceptual understanding. Drawing upon Vygotsky's views on the dialectic relation between tool use and cultural practices, it is important to understand and carefully plan the role of tools in a learning process (Vygotsky, 1986; Wertsch, 1998). As a point of departure, we follow Hoyles \& Noss (2003) in observing that tool characteristics do affect student learning:

Tools matter: they stand between the user and the phenomenon to be modeled, and shape activity structures. (Hoyles \& Noss, 2003, p. 341)

Instrumentation theory focuses on the mediating role of tools by stressing the co-emergence of tool techniques and meaning in a process of instrumental genesis (Artigue, 2002; Trouche, 2004). Instrumental genesis comprises the development of cognitive schemes containing conceptual understanding and techniques for using a tool for a specific type of task. The resulting instrument integrates the tool and mental schemes. As a consequence, a bilateral relationship between the tool and the user exists: While the student's knowledge guides the way the tool is used and in a sense shapes the tool, the affordances and constraints of the tool influence the student's problem-solving strategies and the corresponding emergent conceptions.

Instrumentation theory reveals the problems that may arise when starting to use a ready-made computer tool and explains the importance of aligning techniques that emerge in the contextual problems with the techniques in the learning arrangement with computer tools. Instrumental genesis can be hindered by discrepancies between tool techniques and conventional paperand-pencil techniques (Drijvers et al., 2007). These insights help us to avoid 
students carrying out computer tasks satisfactorily without mastery of the underlying mathematical concepts and not knowing what to do in problem situations without the tool at hand (Hennessy, Ruthven \& Brindley, 2005). For instance, we inserted preliminary paper-and-pencil activities as a preparation on techniques with the computer tool and carefully sequenced the use of tool options in the learning arrangement.

In general, computer tools are able to dynamically and flexibly deal with different function representations such as tables, graphs, and formulas (Ponte, 1992). This may help to overcome the difficulty of integrating the operational and structural aspects of the function concept and its different representations (Falcade et al., 2007). Computer tools can support exploratory activities for coordinating dependency relationships and investigating the dynamics of co-variation (Kaput \& Schorr, 2007). In this particular study, a computer applet called AlgebraArrows is used to support the transition from a calculation understanding to an object understanding of functions. The tool, together with the tasks that aim to exploit the tool's affordances, will be presented in more detail in the "Methods" section.

\section{Methods}

The design of, and teaching experiments with, the learning arrangement not only aim at fostering students' functional thinking, but also at an understanding of why the particular instructional setting potentially supports learning. This requires cumulative cyclic, classroom-based design research that allows for analyzing and improving learning arrangements (Gravemeijer \& Cobb, 2006). Design research involves formulating, testing and refining conjectures, designing instructional activities, and teaching experiments with these activities. The conjectures provide for a connection between the teaching experiments and an understanding of how students can be supported in the development of functional thinking. Such a progression should take into account both the cognitive development of the individual students, as well as the social context in which the teaching experiments are to take place (Cobb \& Yackel, 1996; Gravemeijer \& Cobb, 2006). We describe successively the design phase, teaching experiments and analysis in this research.

\section{Design Phase}

An important part of the design phase involved both the literature study which led to the theoretical framework described in section "Theoretical Framework," 
and the design of the learning arrangement. In this section, we report on the design as it resulted from the sequence of three design cycles. As such, it is an important result from the study.

The learning arrangement includes (a) a computer tool called AlgebraArrows, (b) a student textbook with both paper-and-pencil and computer tasks, (c) a teacher guide describing the various activities and their possible orchestrations, and (d) a computer and written test. ${ }^{1}$

The computer tool is an applet called AlgebraArrows, which allows for the construction and use of chains of operations (so-called arrow chains) and provides options for creating tables, graphs, and formulae and for scrolling and tracing. Figure 1 shows an AlgebraArrows window, in which students create and use their representations.

AlgebraArrows is meant to support the construction of input-output chains of operations as a model of a dependency relationship. The applet is embedded in an electronic learning environment, and the researchers, as well as the teacher, can monitor and compare the students' responses with class results. The activity of investigating this applet in pairs is expected to foster a learning process of 'trial-and-improve' and 'negotiation-ofmeaning'. During these investigations, students can find patterns and develop functional thinking while dealing with dynamic input-output dependencies. As such, the computer tool is expected to provide students

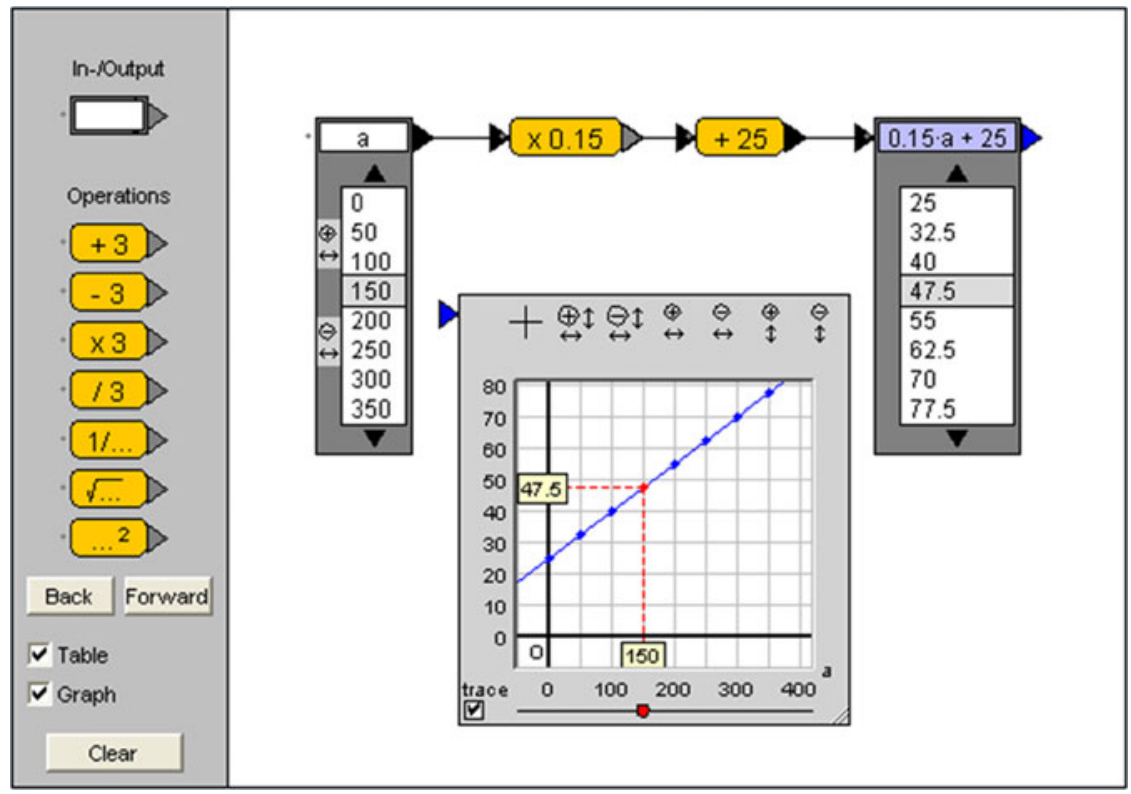

Figure 1. The computer tool AlgebraArrows 
with a means to structure inquiry about dependency relationships through constructing and modifying arrow chains and through generating and comparing argumentations.

The student textbook describes the activities for eight lessons. The learning arrangement starts with three open-ended small-group activities about different dependency relationships:

- A first one on the area of a flexible quadrilateral, which students first explore using a paper model and which then leads to choosing a variable and finding a linear formula.

- A second one on the comparison of two cell phone offers, with a focus on break-even points, which have proved to be suitable problem situations for addressing the concept of function (Ainley, Bills \& Wilson, 2005; Kalchman \& Koedinger, 2005; Küchemann, 1981). As in the first activity, the functions involved are linear.

- A third one on the braking distance of a scooter for various speeds. It includes a quadratic function.

These three activities are meant to create an exploratory stage that reveals the students' current thinking, creates the need for organizing series of calculations, and provides opportunities for the teacher to introduce the computer tool. The students are asked to show their reasoning on posters that are discussed with the whole class. This discussion focuses on differences and similarities between the three problem situations and their solutions for reaching consensus about a model of a series of calculations (an arrow chain) as a sensible way to proceed when investigating dependency relationships. This way, lessons with paper-and-pencil in the regular classroom prepare for lessons in the computer lab, which is meant to promote the integration of both conventional and computer tool techniques.

After these three initial lessons, the arrangement continues with two computer lessons. During the computer activities, students use the computer tool to construct input-output chains of operations as representations of calculation procedures. The chains can be applied to single numerical values as well as to variables, and corresponding tables, formulas, and (dot) graphs can be created (Boon, 2008; Drijvers et al., 2007). To shift focus towards the inquiry of dependency relationships, students are confronted with breakeven problems that ask for the generation and comparison of tables of input and output values, and moving around in a space of possible values. This way, the computer tool's slider bar and table scrolling options, in conjunction to the tasks, invite the students' development of a dynamic notion of a variable (see Figure 1). 
The computer activities are expected to offer students opportunities for creating new mathematical goals that relate to co-variation and functions as mathematical objects. The emergent modeling heuristic suggests a shift from sub-models that signify repeated input-output calculations to models for reasoning about dependency-relationships, co-variation, and of function object properties.

After these five lessons, the arrangement continues with a reflective lesson for aligning computer techniques with paper-and-pencil techniques, and finally a computer lesson with applications and a closing lesson for summarizing results and creating consensus on representations and functional reasoning. In total, the arrangement consisted of eight lessons.

The teacher guide describes the different activities and their possible orchestrations. It suggests different classroom arrangements, such as smallgroup work, poster presentations, computer activities in pairs, and whole class discussions on the results, supported by projections of computer work (Stein, Engle, Smith \& Hughes, 2008). The whole class discussions about students' strategies and inventions are to provide a basis for focusing and converging students' learning and helping them in developing their current thinking in anticipation of future activities (Sherin, 2002). This variety of classroom arrangements, in the intention of the designers, fosters social interaction, which is expected to promote the articulation of tool use and exchange of strategies as well as reflection, generalization, and preparation of what is to come.

The final part of the learning arrangement consists of a computer test and a written test. This mixed media assessment reflects the arrangement as a whole and contains paper-and-pencil questions about break-even points and computer tasks where students could use the applet AlgebraArrows. ${ }^{2}$ Test items in the two tests are comparable in length and difficulty and have similar scoring instructions.

\section{Teaching Experiments and Data Collection}

After a first small-scale pilot study, the learning arrangement was tested and improved in two successive teaching experiments in grade 8 , with mid- and high-achieving 13-14-year-old students. The experiments took eight 50-min lessons. The first teaching experiment was conducted with three classes at three different schools. The second teaching experiment was conducted at a somewhat larger scale. In this paper's analysis, we focus on qualitative screencast data from pairs of students in the first teaching experiment, backed up with quantitative posttest data from 155 students from the second teaching experiment (five classes at two different schools). The students were selected by their teachers based 
upon following criteria we provided: average level of mathematical performance, communicative attitude, and audible articulation.

In both teaching experiments, whole class teaching sessions, group work, and work in pairs were videotaped in two of the participating classes, and, in each of these classes, screencast-audio videos of two pairs of students working with the computer tool were collected. These videos were used to analyze the students' activities during group work and during computer sessions. In addition, students' answers and results to the written and the computer tests administered at the end of the experiment were collected.

\section{Analysis}

The data analyses started with organization, annotation, and description of the data with software for qualitative data analysis (ATLAS.ti ${ }^{3}$; see van Nes \& Doorman, 2010). Initially, the tasks in the learning arrangement served as the unit of analysis for clipping the videos. Codes were used to organize and document the data. Remarkable events from the perspective of the research question were transcribed and discussed in the research team.

In analyzing the first teaching experiment, we constructed a storyline as a reconstruction of the students' learning process. The qualitative data sources were discussed with two external experts to identify illuminating examples of the resulted learning process. This discussion resulted in recognizing a shift in the students' reasoning with functions. Next, illuminating and representative examples for important steps in the shift were identified. In order to investigate this shift quantitatively, we revised the computer activities for the second teaching experiment with a stronger emphasis on break-even points as a motivation for investigating the dynamics of relationships. In addition, we wanted to establish to what extent the students' final performance depended on the use of the available computer tool. We therefore added both a written test and a computer test to the end of the learning arrangement.

To allow for quantitative analyses of these hypotheses in the second teaching experiment, we designed specific paper-and-pencil activities that aimed at investigating these conjectures. We identified characteristics of student answers to codify written student material.

Next, we distinguished solution strategies used on two similar computer tasks that were designed for studying the development of students' reasoning with the computer tool. One task was situated at the beginning of the computer lessons and the other at the end. The strategies led to the construction of codes with respect to the use of representations in the computer tool. These codes could be used to codify screenshots of students' final work on the two computer tasks. 
For the quantitative analyses, we used data from 155 students in five classes. These students concluded the experiment with both the computer test and the written test. For 150 students, we coded their answers to the paperand-pencil activity concerning the arrow chain (the booklets of five students were missing). We coded the screenshots of the answers to the two computer tasks for all 155 students. A second researcher coded 55 out of 306 items (18\%). Good inter-rater-reliability was achieved (with a Cohen's Kappa of 0.79 ) on these items. For a comparison of the results on the written test and the computer test at the end of the learning arrangement, we used a paired $t$ test.

\section{Results}

The results of the study are presented in the form of a storyline of students' learning process. This storyline is illustrated with examples of student work and is empirically supported by quantitative findings.

\section{The Initial Cell Phone Offer Task: Organizing Calculations}

The results of the initial open-ended group activities of the first teaching experiment show a variety of solution strategies. Figure 2 (top) shows the cell phone offer task. The students' posters that describe the two cellphone offers are illustrative for their attempts to organize the situations mathematically, i.e., to organize repeated calculations, construct

Two offers of a cell phone company:

- Tom Seldom: monthly subscription charge $€ 7.50$, plus 25 cents per call minute. The first 30 call minutes are free.

- Tom Often: monthly subscription charge $€ 22.50$, plus 15 cents per call minute. The first 80 call minutes are free.

Nadia calls circa 100 minutes per month. Which offer should she choose, Tom Seldom or Tom Often ?

Find a way to show how the costs of Tom Often vary when you call less or more minutes each month.
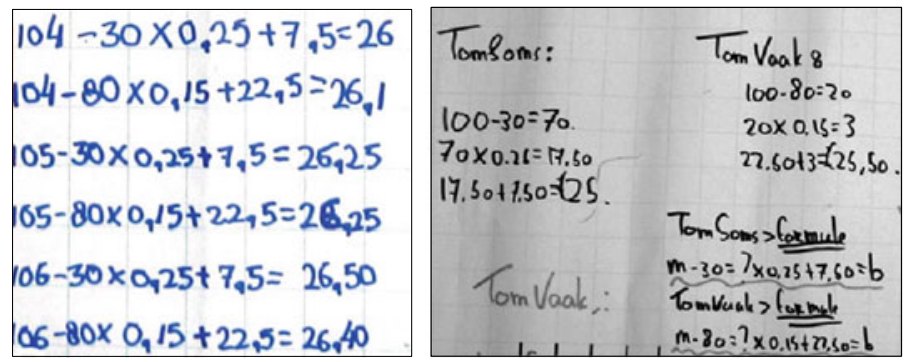

Figure 2. Cellphone offer task and students' posters 
variables, and use various representations. Some students tried to organize their repeated calculations by systematically writing them in a list (left poster in Figure 2). This helped them to see the pattern in the calculation and to apply this pattern to a new input value. In fact, the way in which these students listed their calculations already resembles an input-output relationship (the first number varying over the input values).

The right poster in Figure 2 illustrates attempts of students to use formulas to describe their repeated calculations. Although their formulas are not in conventional form, they show that these students identified the two variables of the dependency relationship ( $m$ for minutes and $b$ for costs). The repeated calculations reflect how the operational aspects precede the structural aspects of functions (Sfard, 1991). The operational aspects were helpful for the teacher during the discussion of the posters in evoking the need for determining variables, dependency relationships, and more efficient notations and tools for finding break-even points.

\section{Introducing Arrow Chains: Visualize Functions}

These results provide support for the argument that rather open problems in the beginning of a learning arrangement can result in various solutions of students that (1) provide information about the students' current thinking and that (2) create starting points for discussing the need for more sophisticated tools.

These strategies were exploited by the teacher by linking the students' initial ideas to the intended tool use during a classroom discussion. During this discussion, new mathematical goals emerged: Repeated calculations are time-consuming; what is the general pattern in the calculation procedures? How can this pattern be described to calculate results 'automatically'? How could a 'calculator' help in comparing cellphone offers?

A calculation recipe that exists of a fixed chain of operations emerged from these activities. This arrow chain is the central representation of the computer tool. In the next activity, the last one before the computer lessons, the students had to draw calculation chains for the two cellphone offers. Figure 3 shows an illustrative answer to the task to construct a calculation chain.

The arrow chain as a model of repeated calculations appeared to be grounded in students' previous activities and could begin to function as a mathematical model for (in terms of the theory of emergent modeling) reasoning about dependency relationships. This assumption is backed up with an analysis of the results of student booklets from the second experiment. The analysis shows that 124 out of 150 students (83\%) drew 


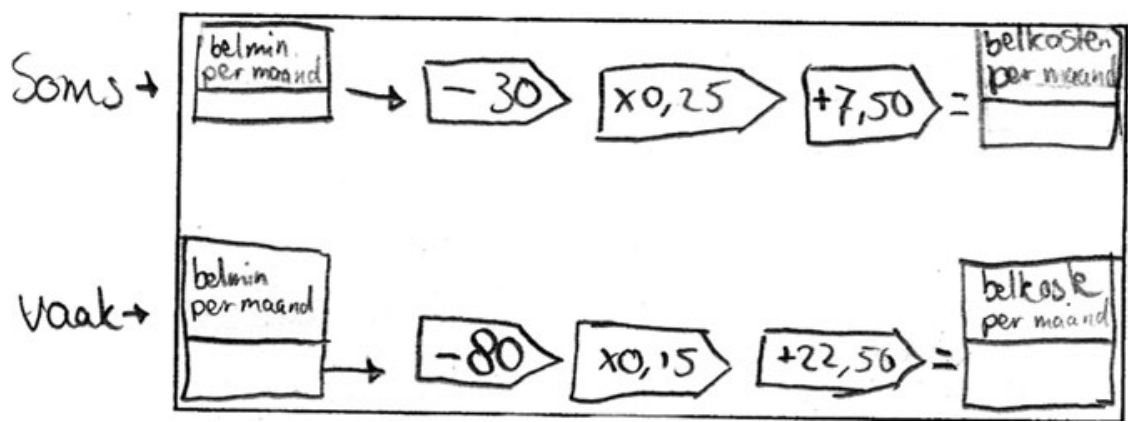

Figure 3. Written calculation chains for cellphone offers (called 'Soms' and 'Vaak')

a similar chain while another eight (5\%) drew this chain, but used it only for one specific calculation and did not label input and output boxes.

\section{Using the Computer Tool to Create Arrow Chains}

The third lesson, the first computer lesson, started with some introductory activities and then continued with the cellphone problem (see Figure 3). The task was to determine, with the computer tool at hand, when it is advisable to change from one offer to the other. Two students, Lily and Rosy, worked together on this task. After reading the problem on the computer screen, they started to construct arrow chains with the computer tool.

[Rosy drags an input box into the drawing area. The box is connected to the operation -80 and that one is connected to $x$ 0.15.]

Lily: And that added to the fixed costs.

$[\mathrm{R}$ agrees and connects the chain to +22.5 . Finally, they connect the chain to an output box.]

L: Well, when you call $100 \mathrm{~min}$

[Enters 100 as input in both chains. TomSeldom (Soms) is cheaper than the other offer.]. R: .... Well, maybe 50.

[L enters 50 as input for both chains. They look at the results and are still not satisfied. They try some more input values. Finally, they enter 200 in the input box of both chains. For the first time TomOften (Vaak) is cheaper than the other offer. They are satisfied with this result and proceed to the next task.]

The vignette illustrates how the arrow chain has become a means to organize the situation and the calculation procedure. Lily and Rosy built the chain from the input box, adding operations and finally connecting an output box. This construction signifies their previous calculations. They focused on specific cases by entering respectively $100,50 \ldots$ and finally 200 for comparing the differences between the two offers. The arrow chain is used for repeated calculations. 


\section{Using the computer tool to create reverse chains}

One of the following questions was to construct a reverse calculation chain for calculating the number of calling minutes when you know the total costs. The following vignette shows how three students (Ali, Bert, and Carl) discussed their reverse arrow chain by using the dimensions of the involved variables.

A: You subtract that from that [points to total costs and the monthly fee] that results in an amount.

B: Yes, say 10 euros.

A: And then you divide it by ... what do you get ... per minute or ...?

B: per minute.

A: Well, then you subtract 22,50 euro and divide it by 15 cent, and this results in minutes, and then you add 80 , that are the free minutes which you receive.

(...)

$\mathrm{C}$ : amount-amount and that is still an amount and you divide that by an amount, 15 cent [the costs per calling minute]. The result is a number, not an amount, and that are calling minutes.

The students had to stepwise analyze and unpack the function chain and to reverse the operations with help of their contextual meaning. This vignette illustrates how the contextual activity on the reverse arrow chain afforded an understanding of the structure and the aim of the chain. The tool technique to construct chains supports this, and the chain became a means for analyzing and discussing relationships and successive operations, as a sequel to merely solving repeated calculations.

\section{Whole-class Discussion Capitalizing on Hands-on Experience}

The start of the second computer lesson, the fourth in the learning arrangement, consisted of a teacher guided classroom discussion of students' computer work by using a beamer. Topics of discussion were the possibility to label input and output boxes and to use tables. These tool techniques were already used by some of the students and now became 'institutionalized' through the whole class discussion. The teacher starts the discussion with an arrow chain for one of the cell phone companies.

T: I heard different ways to find out how much I have to pay, how the amount changes, how can you demonstrate that? [Silence] For example if I call 10 min. What ways do I have to find out how much I pay for $10 \mathrm{~min}$ ?

S1: Put 10 in the input box

$\mathrm{T}$ enters 10 into the input box. This gives an odd result (first 30 free minutes are subtracted). The result is discussed and the teacher varies the input by entering some more values.

T: Suppose I want to know the output from many input values, what more can I use?

S1: The table. 
$\mathrm{T}$ clicks for the table tool and shows how you can scroll through the input and output values.

T: Does anyone know another way to show how the output values change for different input values?

S2: With a graph ...

After this suggestion, the teacher clicks for the graph tool. She demonstrates how to connect an arrow chain to the graph window. Furthermore, together with the students, she investigates the possibilities to trace a graph and to zoom in and out. In this way, together with demonstrating the tool techniques, the teacher discusses aspects of dependency relationships and how tables and graphs can be used to analyze their dynamics. In the previous computer activities, Lily and Rosy did sometimes click for a table or graph, but didn't use it for scrolling or tracing values.

This vignette shows how the teacher used the computer tool to create whole class consensus on how to use it for investigating input-output relationships. Both the techniques and related concepts were part of the discussion. She did not show how to use these features for finding breakeven points. That was still a task for the students.

\section{A Different View on Function}

During the third computer lesson, the sixth lesson of the learning arrangement, we observed that the strategy of Lily and Rosy for using the computer tool had changed while solving a question about two handyman offers by contractors called Pieters and Tweehoog (see Figure 4). The task is quite similar to the cellphone activity. However, the way in which they analyzed the problem situation, phrased the structure of the solution procedure, and how they used the representations in the tool changed from case-by-case calculations to investigating the dynamics of relationships with the tools at hand. In the following vignette, Lily starts the discussion and operates the mouse and the keyboard.

L: Company Pieters charges start costs and an hour rate ... that is ...

R: Plus 92, times $30 \ldots$

To get some jobs done in the house we can choose from two contractors: Contractor "Pieters" charges 92 start costs and an hourly rate of 30.

Contractor "Tweehoog" charges 45 start costs and an hourly rate of 32,75. You have a job of 9 hours. How much cheaper is Tweehoog than Pieters? After how many hours of work is contractor Pieters cheaper than Tweehoog?

Figure 4. Handyman task 
[L drags an input and an output box into the drawing area and creates a label for the in-box]

L: First company Pieters ... I write only Pieters here, eh?

R: Euro ... plus costs per hour Pieters ... and the total costs will come in here.

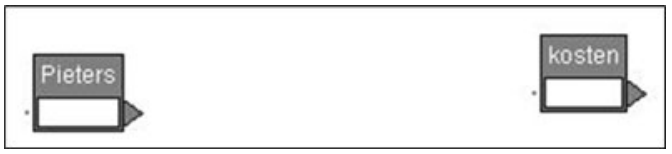

[The mouse moves from inbox to outbox and she creates a label and types the name of the outbox. The variables are identified.]

L: Yes, here are the costs.

[The chain of operations is constructed and connected to the input and output boxes]

(...)

$\mathrm{L}$ : And the other is TweeHoog ...

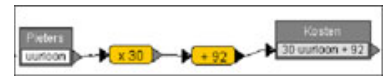

[The inbox and outbox are positioned in the drawing area. Labels are created according to the corresponding variables, with 'uurloon' for 'hourly rate' and interpreted as number of hours.]

R: Strange costs per hour 32.75 .

[The arrow chain of operations is constructed.]

R: Now you have to connect it to a table.

[They start to scroll in the table of the input values and quickly see that the break-even point is at $18 \mathrm{~h}$.

(...)

L\&R: From $18 \mathrm{~h}$.

[They type in their answer: from $18 \mathrm{~h}$.]

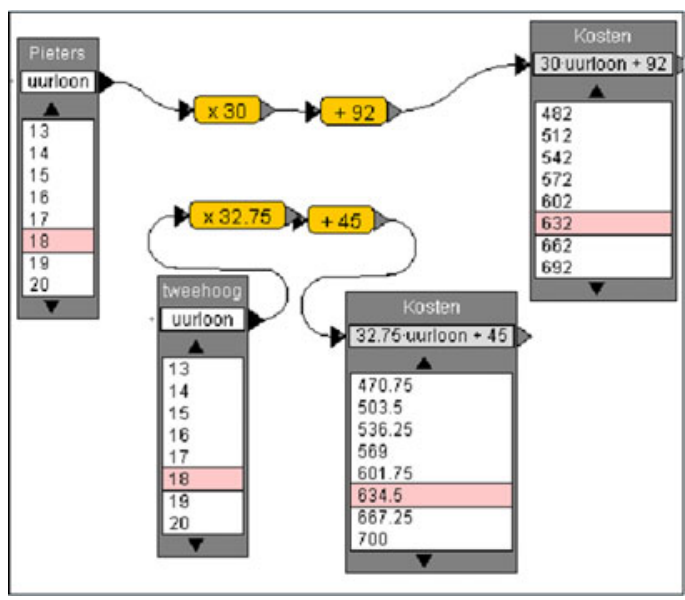

This vignette illustrates a different view on, and use of, the arrow chain compared to the initial operational left-to-right construction of a chain for 
repeated calculations. More specifically, the vignette illustrates how the arrow chain had become a tool for analyzing dependency relationships. Lily and Rosy organized the dependency relationship by identifying, positioning, and labeling boxes for input and output variables and filling the gap between them with operations. This construction signifies an understanding of the problem as a question about two dependency relationships. For investigating the dynamics, they successfully operated the table tool to zoom in and out for finding the break-even point. The students' understanding of the problem and phrasing of the related mathematical goals changed and new goals did emerge (e.g. what are the involved variables?).

\section{Backing Up Case Study Findings}

The second teaching experiment was used to quantitatively verify this conjecture concerning the shift in tool use during the computer activities. We found that for the initial task 130 out of 155 students $(84 \%)$ used the tool for just calculating successive input-output values, while in the task at the end, 89 out of 152 students (58\%) used the tool for structuring and investigating the dynamics of the relationships.

Whereas the students' initial technique with the applet suggested a procedural view on functions, this more advanced technique reflects a shift towards a structural view. In other words, the shift in the use of the tool reflects the development from viewing calculation recipes as tools for repeated calculations (as processes) to reasoning with structural characteristics of dependency relationships (as objects).

To investigate whether this shift also encompassed students' written work during the eight lessons, we compared the scores of the computer test and the written final test. In a paired $t$ test, we found no significant difference $(p=0.20)$ between the final scores on the written test and the computer test. The correlation of 0.38 between these scores was moderate $(p=0.001)$. This suggests that students who improved their reasoning through the described shift were also shown to benefit from this during the paper-and-pencil test.

\section{Overview of the Findings}

To summarize, we found useful and illuminating pointers to what a sequence on functions might help to achieve. The three preparatory openended group activities, in the beginning of the sequence, offer students an opportunity to start from their own informal representations (see Figure 2). The initial modeling processes resulted in tentative reasoning and representations that the teacher could build on by introducing the arrow chain as model of a calculation recipe. The arrow chain representation 
might derive its meaning from the students' previous activities and might support the emergence of the notion of dependent and independent variables and of chains of operations during the subsequent activities (e.g. identifying, positioning, connecting, and labeling input and output boxes). The notion of arrow chains and varying input values preceded the scrolling through tables and zooming in graphs for finding break-even points. This is a key element of what is denoted 'imagery' in the emergent modeling approach: New representations or sub-models signify earlier activities with earlier representations. Table 1 summarizes this envisioned development.

\section{Conclusion and Discussion}

\section{Conclusion}

The central question we formulated in the introduction of this paper is: How can a learning arrangement with computer tools foster the transition from a procedural calculation understanding to a structural correspondence and covariation understanding of functions? Although the arrangement had the potential to offer students opportunities to work with correspondence and covariation, in which functions represented by arrow chain and tables are starting to become mathematical objects for the students, we cannot claim that all students reached a structural understanding of functions within the timeline of the teaching sequence. Nevertheless, we can identify the following characteristics of a rich learning arrangement that foster a transition from a calculation understanding to working with correspondence and co-variation:

1. The three initial open-ended problems and the poster activity helped students in coming to see input-output structures in problems about dependency relationships and to use representations to explore them.

TABLE 1

Global outline of the intended learning outcomes

Start of the learning arrangement

End of the learning arrangement

\begin{tabular}{lll}
\hline $\begin{array}{l}\text { Task } \\
\text { perception }\end{array}$ & Find value & Find relationship \\
Tool use & $\begin{array}{l}\text { Construct chain (from left to } \\
\text { right) and enter successive } \\
\text { values }\end{array}$ & $\begin{array}{l}\text { Construct chain (after identifying variables) } \\
\text { and scroll table or trace graph }\end{array}$ \\
& Repeated calculations & Dependency relationship \\
\hline
\end{tabular}


2. By enabling students to design and use arrow chains as a means of support for reasoning about calculation recipes that bear meaning in everyday-life phenomena, the computer tool supported the students in developing the notion of a chain of operations.

3. By generating the results of a series of calculations for a variety of input values, the computer tool strengthened the students' notion of a function as a calculation recipe that seizes on input values and produces output values.

4. By generating output values for series of input values, by generating tables of input and output values, and by enabling the students to move up and down along these tables, the computer tool supported the students in developing a dynamic notion of a variable that can move around in a space of possible values.

5. By displaying arrow chains, tables, and graphs, the computer tool offers representations, which the students could construe as affordances for treating functions as objects before they had become objects for them.

6. By discussing students' work with the tool and showing specific features that some of the students discovered, the teacher appeared successful in having most students start using the table representation.

In summary, we conclude that the learning arrangement with a computer tool helped students to overcome the difficulty of integrating operational and structural aspects of the concept function (Falcade et al., 2007; Sfard, 1991). In particular, the use of the tool supported explorative activities for coordinating and investigating the dynamics of co-variation (Kaput \& Schorr, 2007).

\section{Discussion}

Before discussing the conclusions of this study from a theoretical perspective, we first address its limitations. The sequence of eight lessons fostered conceptual development in the domain of functions. However, the possibilities in the final tests were limited for assessing whether all students made a similar step towards a dual conceptualization, with procedural and structural views, of functions. Moreover, the validity of the strategy coding for underpinning the conjecture that emerged from analyzing the screencast-audio videos can be debated. The screen-audio videos and the observations during the computer lessons showed that the final screenshots of an activity sometimes are only poor representations of 
the students' reasoning. Students could be close to a good answer and then delete everything as a result of a sudden doubt. Final screenshots don't capture this entire reasoning process. Additional information is needed for a full understanding of students' conceptual development in relation to their tool techniques. However, the balance between a manageable data collection and as much information as possible will remain a problematic issue for this. A comparison with a control group is needed to better understand to what extent the improvement is the result of this learning arrangement and the computer tool.

Finally, the results cannot be generalized beyond this particular setting. The extensive description of the interventions is intended to enable researchers to implement the experiment in other settings as a way to evaluate our findings and to contribute to the development of a more encompassing theory. This study started from domain-specific theories on the acquisition of the concept of function and theoretical notions of emergent modeling, tool use, and instrumentation. How did the latter two perspectives work out? First, the notion of emergent modeling and its focus on the shift from "model-of" to "model-for," not only guided the design of the learning arrangement; indeed, the students' cognitive development, and their ways of using the tool initially as a tool for calculations and later as a tool for reasoning with function, reflect this shift.

Second, instrumentation theory focuses on the interrelated development of techniques and concepts. The careful integration of computer activities and paper-and-pencil activities prevented discrepancies between tool techniques and conventional paper-and-pencil techniques. The process of instrumental genesis was enhanced by this alternation between classroom discussion, small-group activities, and computer activities. The repertoire of applet techniques, however, was small and comprised rather simple technical skills. Even if we observed changes in how students built arrow chains, the main evolution concerned the reasoning attached to dependency relationships and was not a technical one.

OPEN ACCESS This article is distributed under the terms of the Creative Commons Attribution License which permits any use, distribution, and reproduction in any medium, provided the original author(s) and the source are credited.

ACKNOWLEDGMENTS. This study is part of a project that is supported by The Netherlands Organization for Scientific Research (NWO) with grant number 411-04-123. 


\section{NOTES}

${ }^{1}$ The learning arrangement is available through http://www.fi.uu.nl/tooluse/en/

${ }^{2}$ The full computer and written test can be found at http://www.fi.uu.nl/tooluse/en/

${ }^{3}$ Designed and produced by ATLAS.ti GmbH in Berlin.

\section{REFERENCES}

Ainley, J., Bills, L. \& Wilson, K. E. (2005). Designing spreadsheet-based tasks for purposeful algebra. International Journal of Computers for Mathematical Learning, 10 (3), 191-215.

Akkus, R., Hand, B. \& Seymour, J. (2008). Understanding students' understanding of functions. Mathematics Teaching, 207, 10-13.

Artigue, M. (2002). Learning mathematics in a CAS environment: The genesis of a reflection about instrumentation and the dialectics between technical and conceptual work. International Journal of Computers for Mathematical Learning, 7, 245-274.

Bereiter, C. (1985). Towards a solution of the learning paradox. Review of Educational Research, 55(2), 201-226.

Bloch, I. (2003). Teaching functions in a graphic milieu: What forms of knowledge enable students to conjecture and prove? Educational Studies in Mathematics, 52 (1), 3-28.

Boon, P. (2008). AlgebraArrows. Retrieved at June 9th, 2008, from http://www.fi.uu.nl/ wisweb/en/welcome.html.

Breidenbach, D., Dubinsky, E., Hawks, J. \& Nichols, D. (1992). Development of the process conception of function. Educational Studies in Mathematics, 23, 247-285.

Carlson, M., Jacobs, S., Coe, E., Larsen, S. \& Hsu, E. (2002). Applying covariational reasoning while modeling dynamic events: A framework and a study. Journal for Research in Mathematics Education, 33, 352-378.

Cobb, P. (2002). Reasoning with tools and inscriptions. The Journal of the Learning Sciences, 11(2\&3), 187-215.

Cobb, P. \& Yackel, E. (1996). Constructivist, emergent, and sociocultural perspectives in the context of developmental research. Educational Psychologist, 31 (3/4), 175-190.

Doorman, L. M. \& Gravemeijer, K. P. E. (2009). Emergent modeling: discrete graphs to support the understanding of change and velocity. ZDM-International Journal on Mathematics Education, 41, 199-211.

Drijvers, P., Doorman, M., Boon, P., Van Gisbergen, S. \& Gravemeijer, K. (2007). Tool use in a technology-rich learning arrangement for the concept of function. In PittaPantazi, D., \& Philippou, G., Proceedings of CERME 5, 1389-1398.

Dubinsky, E. (1991). Reflective abstraction in advanced mathematical thinking. In D. O. Tall (Ed.), Advanced mathematical thinking (pp. 95-123). Dordrecht: Kluwer.

Duval, R. (2006). A cognitive analysis of problems of comprehension in a learning of mathematics. Educational Studies in Mathematics, 61, 103-131.

Elia, I., Panaoura, A., Eracleous, A. \& Gagatsis, A. (2007). Relations between secondary pupils' conceptions about functions and problem solving in different representations. International Journal of Science and Mathematics Education, 5, 533-556. 
Even, R. (1998). Factors involved in linking representations of functions. The Journal of Mathematical Behavior, 17, 105-121.

Falcade, R., Laborde, C. \& Mariotti, M. A. (2007). Approaching functions: Cabri tools as instruments of semiotic mediation. Educational Studies in Mathematics, 66, 317-333.

Freudenthal, H. (1983). Didactical phenomenology of mathematical structures. The Netherlands: Reidel: Dordrecht.

Freudenthal, H. (1991). Revisiting mathematics education-China lectures. Dordrecht: Kluwer Academic Publishers.

Gravemeijer, K. (1999). How emergent models may foster the constitution of formal mathematics. Mathematical Thinking and Learning, 1, 155-177.

Gravemeijer, K. (2007). Emergent modelling as a precursor to mathematical modelling. In W. Blum, P. L. Galbraith, H.-W. Henn, \& M. Niss (Eds.), Modelling and applications in mathematics education. The 14th ICMI Study (pp 137-144). New York: Springer.

Gravemeijer, K. P. E., Lehrer, R., van Oers, B., \& Verschaffel, L. (Eds.). (2002). Symbolizing, modeling and tool use in mathematics education. Dordrecht, the Netherlands: Kluwer Academic Publishers.

Gravemeijer, K., \& Cobb, P. (2006). Design research from the learning design perspective. In J. van den Akker, K. Gravemeijer, S. McKenney, \& N. Nieveen (Eds.), Educational design research (pp. 17-51). London: Routledge.

Hennessy, S., Ruthven, K. \& Brindley, S. (2005). Teacher perspectives on integrating ICT into subject teaching: commitment, constraints, caution and change. Journal of Curriculum Studies, 37(2), 155-192.

Hoyles, C. \& Noss, R. (2003). What can digital technologies take from and bring to research in mathematics education? In A. J. Bishop, M. A. Clements, C. Keitel, J. Kilpatrick \& F. K. S. Leung (Eds.), Second international handbook of mathematics education (pp. 323-349). Dordrecht: Kluwer Academic Publishers.

Janvier, C. (1987). Translation processes in mathematics education. In C. Janvier (Ed.), Problems of representation in teaching and learning mathematics (pp. 27-32). Hillsdale: Lawrence Erlbaum Associates.

Kalchman, M. \& Koedinger, K. (2005). Teaching and learning functions. In S. Donovan \& J. Bransford (Eds.), How students learn mathematics (pp. 351-392). Washington DC: National Academy of Sciences.

Kaput, J. \& Schorr, R. (2007). Changing representational infrastructures changes most everything: The case of SimCalc, algebra and calculus. In G. W. Blume \& M. K. Heid (Eds.), Research on technology and the learning and teaching of mathematics: Vol. 2 cases and perspectives (pp. 211-253). Charlotte: Information Age Publishing.

Kuchemann, D. (1981). Algebra. In K. Hart (Ed.), Children's understanding of mathematics:11-16 (pp. 102-119). London: Murray.

Lehrer, R. \& Schauble, L. (2002). Symbolic communication in mathematics and science: Constituting inscription and thought. In E. D. Amsel \& J. Byrnes (Eds.), Language, literacy, and cognitive development. The development and consequences of symbolic communication. (pp. 167-192). Mahwah, NJ: Lawrence Erlbaum Associates.

Malle, G. (2000). Zwei Aspekte von Funktionen: Zuordnung und Kovariation. Mathematik Lehren, 103, 8-11.

Meel, D. (1998). Honors students' calculus understandings: Comparing Calculus\&Mathematica and traditional calculus students. In Shoenfeld, A., J. Kaput, \& E. Dubinsky 
(Eds.) CBMS Issues in Mathematics Education 7: Research in Collegiate Mathematics Education III. pp. 163-215.

Meira, L. (1995). The microevolution of mathematical representations in children's activity. Cognition and Instruction, 13, 269-313.

Oehrtman, M. C., Carlson, M. P. \& Thompson, P. W. (2008). Foundational reasoning abilities that promote coherence in students' understandings of function. In M. P. Carlson \& C. Rasmussen (Eds.), Making the connection: Research and practice in undergraduate mathematics (pp. 27-42). Washington DC: Mathematical Association of America.

Pirie, S. E. B. \& Kieren, T. E. (1989). A recursive theory of mathematical understanding. For the Learning of Mathematics, 9(3), 7-11.

Ponce, G. (2007). Critical juncture ahead: Proceed with caution to introduce the concept of function. Mathematics Teacher, 101(2), 136-144.

Ponte, J.P. (1992). The history of the concept of function and some educational implications. The Mathematics Educator, 3(2), 3-8. Retrieved April, 2nd, from http:// math.coe.uga.edu/TME/Issues/v03n2/v3n2.html.

Rasmussen, C. \& Blumenfeld, H. (2007). Reinventing solutions to systems of linear differential equations: A case of emergent models involving analytic expressions. The Journal of Mathematical Behavior, 26, 195-210.

Sfard, A. (1991). On the dual nature of mathematical conceptions: Reflections on processes and objects as different sides of the same coin. Educational Studies in Mathematics, 22, 1-36.

Sfard, A. \& McClain, K. (2002). Special issue: Analyzing tools: Perspective on the role of designed artifacts in mathematics learning. The Journal of the Learning Sciences, 11, $153-388$.

Sherin, M. G. (2002). A balancing act: Developing a discourse community in a mathematics community. Journal of Mathematics Teacher Education, 5, 205-233.

Skaja, M. (2003). A secondary school student's understanding of the concept of function -A case study. Educational Studies in Mathematics, 53(3), 229-254.

Slavit, D. (1997). An alternate route to the reification of function. Educational Studies in Mathematics, 33, 259-281.

Stein, M. K., Engle, R. A., Smith, M. S. \& Hughes, E. K. (2008). Orchestrating productive mathematical discussions: Five practices for helping teachers move beyond show and tell. Mathematical Thinking and Learning, 10(4), 313-340.

Tall, D. (1996). Functions and calculus. In A. J. Bishop, K. Clements, C. Keitel, J. Kilpatrick \& C. Laborde (Eds.), International handbook on mathematics education (pp. 289-325). Dordrecht: Kluwer Academic Publishers.

Trouche, L. (2004). Managing complexity of human/machine interactions in computerized learning environments: Guiding students' command process through instrumental orchestrations. International Journal of Computers for Mathematical Learning, 9, 281-307.

van den Heuvel-Panhuizen, M. H. A. M. (2003). The learning paradox and the learning miracle: Thoughts on primary school mathematics education. ZDM-International Journal on Mathematics Education, 24, 96-121.

van Nes, F. T. \& Doorman, L. M. (2010). The interaction between multimedia data analysis and theory development in design research. Mathematics Education Research Journal 22(1), 6-30. 
Vinner, S. \& Dreyfuss, T. (1989). Images and definitions for the concept of function. Journal for Research in Mathematics Education, 20(4), 356-366.

Vygotsky, L. S. (1986). Thought and language—Rev'd edition. Cambridge: A. Kozulin. The MIT Press.

Wertsch, J. V. (1998). Mind as action. New York: Oxford University Press.

Freudenthal Institute for Science and Mathematics Education

Utrecht University

Princetonplein 5, 3584 CC Utrecht, The Netherlands

E-mail:m.doorman@uu.nl 